Resumo Pôster CoP-Rede Onco

\title{
Mapeamento de parceiros para desenvolvimento de bioprodutos voltados ao tratamento de neoplasias.
}

Aline de Almeida Oliveira, Ana Paula Dinis Ano Bom, Ana Paula Carvalho, Gisele Corrêa Miranda,

Patrícia Cristina da Costa Neves

Bio-Manguinhos/Fiocruz

\section{Introdução}

O envelhecimento, a urbanização, as mudanças sócio-econômicas e a globalização impactaram o modo de viver dos brasileiros nos últimos anos. Segundo dados do Ministério da Saúde e do IBGE, estes fatores provocaram profunda mudança no padrão de morbimortalidade da população brasileira. Sabe-se que houve redução importante das mortes por doenças infecciosas e parasitárias, ao passo que se observou um incremento por doenças crônico-degenerativas, principalmente as neoplasias, que já representam a segunda causa de morte no país. Diante deste quadro, Bio-Manguinhos tem pela frente enormes desafios no que diz respeito ao desenvolvimento de produtos inovadores para o combate a estas doenças que possam ser incorporados ao Sistema Único de Saúde. Estas novas demandas trazem uma urgência para a reunião de especialistas, arranjados em redes de colaboração, que auxiliem o desenvolvimento destes novos produtos, já que esta é uma área de atuação relativamente nova para a instituição e que o conceito de colaboração e união de expertises vem se consolidando desde o início da década de 90 como a melhor alternativa para atender à crescente demanda por resposta a desafios de complexidade crescente. Neste sentido, em junho de 2014, foi criada Comunidade de Prática para a discussão de temas na área de oncologia (CoP-Rede-Onco), com o intuito de buscar e trocar informações, para o compartilhamento de experiências, e para estimular a estruturação de parcerias que resultassem em redes de colaboração sob coordenação direta de Bio-Manguinhos. 


\section{Objetivo}

O objetivo do trabalho foi mapear e identificar possíveis parceiros para acelerar o desenvolvimento de produtos inovadores para o tratamento de neoplasias.

\section{Metodologia}

A prospecção de potenciais parceiros foi feita a partir de pesquisa na base de dados do diretório de grupos de pesquisa do CNPq, utilizando-se como palavra chave "câncer". A partir dos dados obtidos, foi feita uma seleção dos grupos, de acordo com a área de atuação de cada um, de modo que os possíveis parceiros pudessem ser encaixados em 5 temas previamente definidos como gargalos para o desenvolvimento de produtos em BioManguinhos.

\section{Resultados}

A pesquisa resultou na identificação de 750 grupos de pesquisa cadastrados no CNPq no tema "câncer". Estes grupos foram avaliados individualmente quanto à linha de pesquisa e, dos 750 grupos, foram selecionados 81 com potencial para colaboração, obedecendo a uma classificação em 5 temas, de maneira a aumentar a capacidade inovadora e resolução de gargalos, auxiliando diversos projetos de desenvolvimento tecnológico em BioManguinhos. Os temas escolhidos foram: novos alvos para diagnóstico, prognóstico e terapia, tecnologias de suporte, modelos animais para câncer e estudos clínicos. Já estão em andamento projetos iniciais com alguns destes colaboradores.

\section{Conclusões}

Esse mapeamento está sendo de extremo valor na identificação de alianças estratégicas visando o desenvolvimento de novos produtos na área de Oncologia. 